\title{
RULES OF ORDER IN THE RETINOTECTAL FASCICLES OF GOLDFISH $^{1}$
}

\author{
CLAUDIA A. O. STUERMER ${ }^{2}$ AND STEPHEN S. EASTER, JR. ${ }^{3}$ \\ Division of Biological Sciences, University of Michigan, Ann Arbor, Michigan 48109
}

Received August 24, 1983; Revised October 26, 1983; Accepted October 27, 1983

\begin{abstract}
Individual fascicles of retinal axons were labeled in the goldfish tectum with horseradish peroxidase (HRP). The contralateral retina was later processed for HRP histochemistry to mark the cells that had axons in the fascicles. Labeled cells were found in a partial half anulus in ventral hemiretina, centered on the optic disk. The distance of the partial anulus from the disk depended on which tectal fascicle had been labeled; the more rostrocentral the fascicle, the smaller was the annular radius. The angular subtense of the partial anulus with respect to the disk depended on where (along its tectal course) the fascicle had been labeled; the more rostral the label site, the longer was the angular subtense. These results were interpreted in the context of retinotectal growth, and it was inferred that the axons followed two rules: (1) grow in along the edge of the tectum and (2) exit and terminate in order, axons from temporal retina first, nasal retina last. These rules would produce a retinotopic projection in peripheral tectum, but they require that some of the terminals already in place must shift as the tectum grows.
\end{abstract}

Axons from the retinal ganglion cells of vertebrates course to the brain through the optic nerve and tract. An important target is the optic tectum, where axons from neighboring retinal ganglion cells arborize in neighboring regions to create the "retinotectal map." This topographic projection between the two hemispheric surfaces, which is quite reproducible in all individuals of the same species, exemplifies the precise interneuronal connectivity which is thought to be essential to most organized neural functions. Accordingly, the map has been studied extensively in both fish and amphibians with behavioral (Sperry, 1944; Schwassmann and Krag, 1970), anatomical (Attardi and Sperry, 1963; Meyer, 1980), and electrophysiological (Jacobson and Gaze, 1964; Schwassmann and Kruger, 1965) methods. Most previous studies emphasized the relationships between the retinal addresses of the ganglion cell bodies and the tectal addresses of their terminal arbors. This paper emphasizes the pathways taken by the axons.

${ }^{1}$ We thank Mr. Bradford Bratton for technical assistance, and Drs. P. A. Raymond, W. J. Crossland, P. Hitchcock, and Mr. S. Scherer for useful comments on the paper. This work was supported by National Fye Institute of the National Institutes of Health Grant FY-00168 to S. S. E. and Deutsche Forschungsgemeinschaft Grant DFG Stu 112 to C. A. O. S.

${ }^{2}$ Current address: Max Planck Institut fur Virusforschung, Abt. Physikalische Biologie, Spemannst. 34, D7400 Tubingen, West Germany.

${ }^{3}$ To whom correspondence should be addressed, at the Salk Institute for Biological Studies, P. O. Box 85800, San Diego, CA 92138.
The pathways are well known, on a gross level. In goldfish, the optic tract bifurcates into the dorsal and ventral brachia, which innervate the two hemitecta, dorsal and ventral, with axons from the ventral and dorsal hemiretinas, respectively. The tectum is roughly hemispheric, with the rim oriented approximately vertically and the convex surface facing laterally. The brachia course rostrocaudally along the dorsal and ventral tectal rims, and from them issue two symmetric fan-like arrays of fascicles (Fig. 1). Pairs of fascicles, one dorsal, one ventral, diverge where the tract bifurcates and then meet again at the equator, the boundary between dorsal and ventral hemitecta (Fig. 1c). Thus, individual pairs trace out a circle. The set of paired fascicles approximates a nested set of circles, all tangent to one another rostrally (Fig. 2a).

Recently, small groups of axons have been selectively visualized in the hope of elucidating the organization of the pathways in more detail. In fish, the axons within any individual bundle in the nerve originate in a retinal anulus roughly concentric with the retinal margin (Scholes, 1979; Bodick and Levinthal, 1980; Rusoff and Easter, 1980). This has developmental implications, because the retina grows by adding ganglion cells to its margin (Müller, 1952; Johns, 1977). As a result, each generation of ganglion cells occupies a retinal anulus peripheral to older generations and central to younger ones. Therefore, a bundle's origin from an anulus implies that the axons in the bundle have the same age, and the centroperipheral position of the anulus indicates the age. 
The rules of organization in the brachia and in the intratectal fascicles have not been worked out, but it is known that the youngest axons course together in the most peripheral tectal fascicles, parallel to the rim (Rusoff, 1980; Easter et al., 1981). This implies that the axons that were together in the tract remain together in the tectum, at least while they are young. If older axons had kept their original neighbors, then the fascicles in more central tectum might also be ordered by age, a possibility which has not previously been considered.

The prevailing opinion of how the tectal fascicles are ordered is derived from the classic study of optic nerve regeneration by Attardi and Sperry (1963). They concluded that severed retinal axons regenerated across tectum directly toward their termination sites. Later authors explicitly assumed that normal axons took similarly direct routes (Horder, 1974; Meyer, 1979). If so, then axons should terminate in the vicinity of the fascicle through which they enter the tectum. For reasons to be explained below, this seems unlikely. Therefore, we sought to learn the retinal origins of the axons in the tectal fascicles. This relatively narrow question has yielded results with important implications for the establishment of the retinotectal map.

A preliminary account of this work has appeared in an abstract (Stuermer and Easter, 1982).

\section{Materials and Methods}

Adult goldfish, 8 to $30 \mathrm{~cm}$ standard length, were obtained commercially and maintained in aerated aquaria at room temperature $\left(20\right.$ to $\left.30^{\circ} \mathrm{C}\right)$. During all surgical procedures, and prior to sacrifice, the fish were anesthetized in a $0.1 \%$ aqueous solution of tricaine methanesulfonate.

A dorsal flap of cranium was removed to expose the tectum. Individual fascicles on the dorsal hemitectum were severed with a tungsten microneedle, and a small crystal of HRP (Miles type 6) was placed at the interruption. The ventral hemitectum is inaccessible and was not labeled. The cranial opening was closed, and the fish was revived. Several (2 to 4 ) days later, the fish was dark-adapted for 2 to $3 \mathrm{hr}$ to facilitate removal of the retina, anesthetized, and the eye and brain were removed. A razor cut was made on the dorsal pole of the eye for purposes of orientation later on. Then the lens, cornea, and iris were removed, and the retina was detached from the pigmented epithelium in phosphate buffer. It was important that the entire retina was removed; this was assured by always including the annular blood vessel at the margin. The retina was then cut radially at several points around the margin, flattened between two sheets of lens paper, and fixed for $2 \mathrm{hr}$ in buffered glutaraldehyde. The vitreous was carefully dissected away, and the retina was reacted for HRP with tetramethylbenzidine (TMB) as the chromogen (Mesulam, 1978). The TMB reaction product usually faded within an hour or two, so permanent records of labeled retinas were made either photographically or with a camera lucida drawing or both.

A total of 46 retinas were prepared. In 10 cases, the labeled tectum was also reacted, unfixed, for HRP using diaminobenzidine as the chromogen (Fujisawa et al., 1981) and was then flat-mounted as shown in Figure 1c.

\section{Results}

The selectivity of the labeling method was evident from the flat-mounted tecta. The application site was visible as a puncture wound, surrounded by reaction product, from which emerged one or two fascicles labeled both anterogradely and retrogradely. Retrogradely labeled axons were traced rostroperipherally to one bundle which extended through the brachium, tract, and nerve. This continuity suggests that the age-related order in the nerve and tract (Rusoff and Easter, 1980; Easter et al., 1981) is conserved in the tectal fascicles.

Examination of the whole-mounted retinas reinforced this interpretation. The labeled ganglion cells occupied a portion of a half anulus, concentric with the retinal margin and restricted to the ventral hemiretina (Fig. $2 b$ ). The thickness of the partial anulus ranged from 4 to $8 \%$ of the retinal radius. Typically, half or less of the ganglion cell bodies within the zone were labeled. The partial anulus extended to the nasal boundary between dorsal and ventral hemiretinas but did not reach the temporal boundary (see below).

Fascicles in different positions were labeled in individual fish, in order to relate the position of a fascicle on the tectum to the retinal position of its cells of origin. Sites very near the brachia were usually avoided, particularly in rostral tectum, where all fascicles are tightly packed. The individual label sites were located with the help of camera lucida drawings of the intact tectum at the time of labeling and/or of the whole-mounted tectum after processing for HRP. The label sites were lumped into three groups, indicated in Figure $1 c$, according to whether the labeled fascicle met the equator on the rostral, intermediate, or caudal third. This was estimated at the time the fascicle was labeled. The results are shown in Figure 2c. The abscissa gives the label sites, and the ordinate shows the normalized radius of the retinal anuli, measured along the line connecting the optic disk to the nasal retinal margin. The tectal sites correlated very well with the retinal locations of the labeled anuli. Rostral, intermediate, and caudal fascicles arose from anuli at successively more peripheral positions. We assume that the ventral hemitectum is organized symmetrically.

This basic result was unaffected by the size of the fish used. In nine additional cases, we labeled two separate fascicles and recovered two labeled partial anuli in ventral retina, supporting our conclusion that each partial anulus contributed to a separate fascicle.

We interpret these results in the following way. The cells in each new retinal anulus produce two brachial fascicles which embrace the existing tectum from both dorsal and ventral sides, like the arms of a caliper, and meet at the caudal pole (Fig. $2 a$ ). It is known that the tectum grows by adding new cells appositionally along its dorsal, caudal, and ventral rims (Meyer, 1978; Raymond and Easter, 1983). We suggest that the new tectal tissue encloses the latest generation of axons and creates a new rim along which the next generation of axons will grow. Thus, the fascicles are analogous to the growth rings on a tree, as they define where the outer boundary of the tectum lay when they grew in.

If a new axon is to terminate retinotopically, then it must somehow find the "correct" tectal address. The 


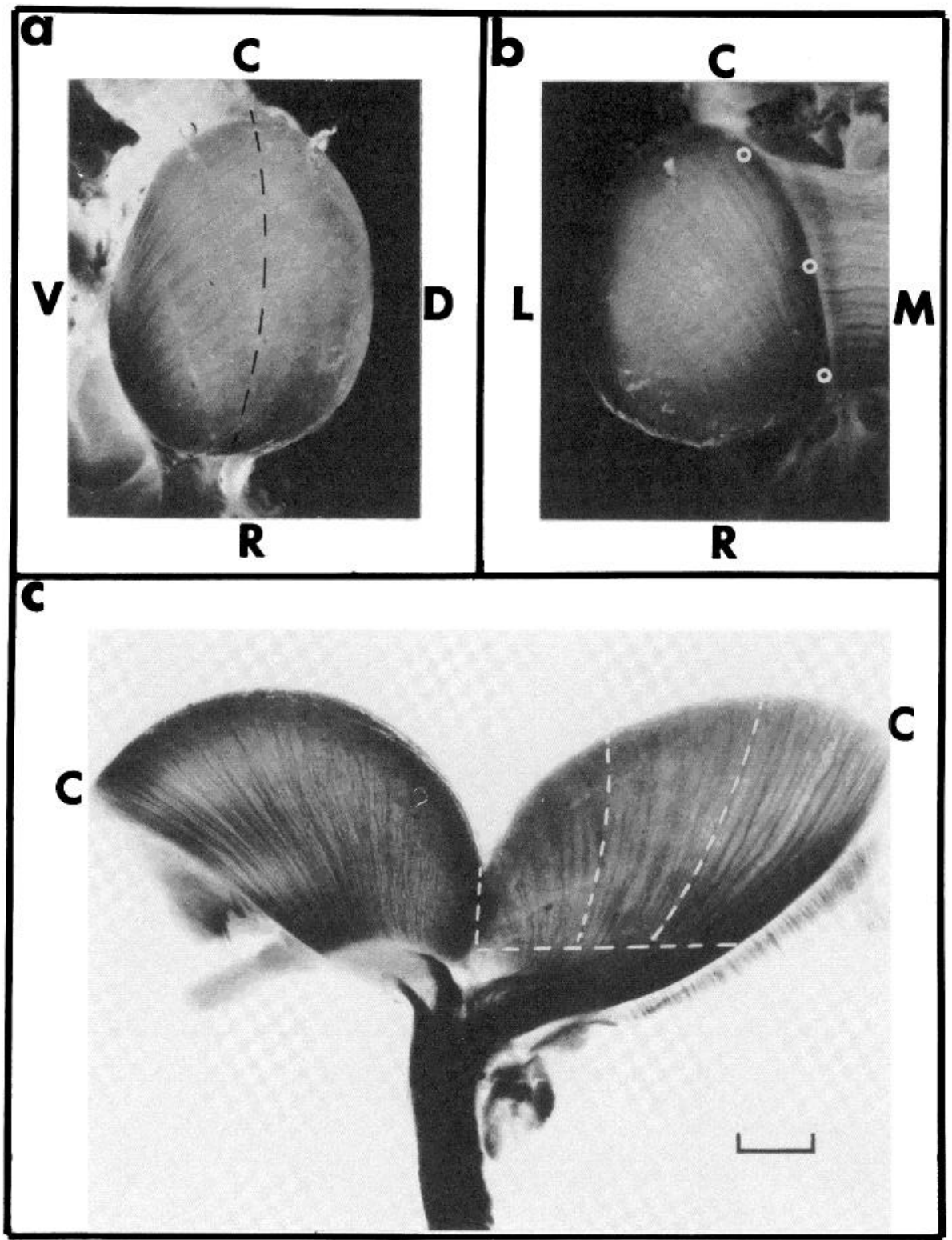

Figure 1. Photographs of the same (right) tectal lobe, prepared by brief fixation in aqueous $\mathrm{OsO}_{4}(\mathrm{Cook}$ and $\mathrm{Horder}, 1977)$ to darken the fascicles of optic axons. $a$, Ventrolateral aspect. The fascicles course from lower left to upper right, toward the equator (dashed line). $b$, Dorsal aspect. The fascicles course from lower right to upper left, toward the equator out of sight on the left. The three white circles show the sites of HRP insertion of Figure $2 d$. $c$, A flattened whole mount of this same tectal lobe, cut along the dotted line in $a$. The upper two curved edges are the two sides of the cut, the right lower edge is the dorsal boundary, and the left lower edge is the ventral. The optic tract is the stalk-like structure below. The dashed lines divide the fascicles into three groups for Figure $2 c$. $C$, caudal; $D$, dorsal; $R$, rostral; $V$, ventral; $L$, lateral; $M$, medial. Calibration: $1 \mathrm{~mm}$.

path of ingrowth is helpful to this search, since it leads to peripheral tectum, where peripheral retina maps. Once in the proper circumferential strip, the growing axon must then exit the fascicle and terminate at the proper location along this strip.

Do the axons exit the fascicle at the sector where they terminate? Or do they exit unsystematically and finally settle in the proper sector after an extrafascicular search? We investigated these questions by labeling the most peripheral fascicle, in different tecta, at one of three different sites along its course (white circles in Fig. 1b). In all cases, a portion of the most peripheral retinal anulus was labeled. It touched the boundary between dorsal and ventral hemiretinas on the nasal side. On the temporal side, the labeled zone ended abruptly, but the location of this border varied systematically with the application site. The more rostral applications labeled longer contours, as shown in Figure $2 d$. The retinal ganglion cells that were labeled by HRP application at one site, but not by application at a more caudal one, must have had axons that exited the fascicle between those two sites. The departure of the axons from the fascicle was systematic; those axons from more temporal retinal positions exited more rostrally; more nasal ones exited more caudally. We know that the temporonasal direction in retina maps onto the rostrocaudal direction 


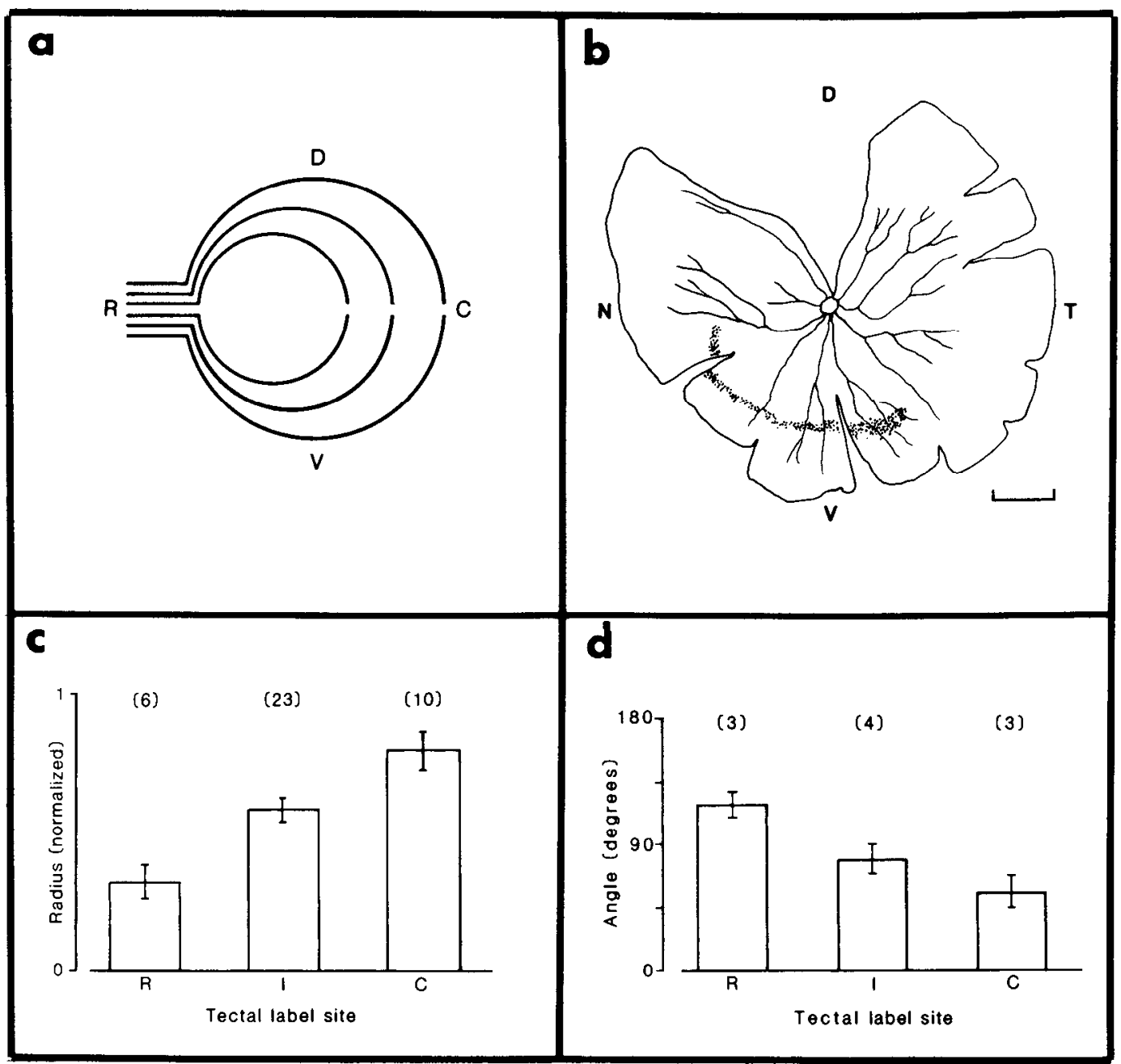

Figure 2. a, Schematic representation of the caliper-like arrangement of the optic fascicles in the brachia and tectum, lateral view. (Compare to Fig. 1.) $b$, Camera lucida drawing of a retinal whole mount, showing the blood vessels radiating from the optic disk and the partial anulus of labeled ganglion cells (dots). Calibration: $1 \mathrm{~mm}$. $c$, The radii of the partial anuli (relative to the maximum retinal radius) plotted versus the tectal label sites shown in Figure $1 c$. Means \pm SEM. Numbers above show numbers of retinas. By the Mann-Whitney $U$ test: $R<I(p<0.005), I<C(p<0.025), R<C(p<0.001)$. $d$, The subtense of the partial anuli plotted versus the tectal label sites shown by the white circles in Figure $1 b$. Conventions are as in $c$. By the Mann-Whitney $U$ test: $C<R(p<0.025), I<R(p<0.05), C<I(p<0.1)$. Abbreviations are as in Figure 1 . $T$, temporal; $N$, nasal; $I$, intermediate. The three retinas in the $\mathrm{C}$ group of $d$ were also included in the $\mathrm{C}$ group of Figure $2 c$.

in tectum (Schwassmann and Kruger, 1965). Therefore, the order of exit in tectum is consistent with the polarity of the retinotopic map.

\section{Discussion}

Relation of the results to map formation. The newest axons grow together in a fascicle along the rim of the tectum; this puts axons from peripheral retina into peripheral tectum. Then the axons exit the fascicle in order-temporal first, nasal last-and terminate near their exit. We suggest that this sequence of events creates the retinotectal map, as the first rule (grow along the rim) puts the axons in the tectal anulus that is topographcally appropriate to the retinal anulus of their cell bodies, and the second rule (exit temporal first, nasal last) puts the axons into the topographically appropriate tectal sector. If we describe the two-dimensional tectal surface in polar coordinates $(r, \theta)$ centered on the midpoint of the equator, then the proper value of $r$ (the radius) is established by the first rule and that of $\theta$ (the angle) by the second.

The idea that the order of the fibers within the pathway would contribute importantly to the retinotectal map is consistent with recent reports from the visual system of Xenopus (Straznicky et al., 1979; Holt and Harris, 1983). But we emphasize that our study has described the pathways and has not analyzed what factors directed the fibers along these pathways. The guidance cues are as obscure as they ever were, but the issue of how axons find their homes in the tectum has been sharpened in goldfish by breaking down the pathfinding process into several steps. Prior to this study, the issue was usually phrased in terms of two questions: (1) What directs the axons into the proper brachium? (2) What directs the axons to their termination site on the tectum? As a result of this work the second of these questions can now be stated as three more specific ones: What directs the axons to the edge of the tectum? What directs 
them to exit from the fascicle in the temporonasal order? What causes them to arborize, once outside of the fascicle?

Shifling lerminals. The two rules produce an orderly retinotectal map only in the periphery and force the rearrangement of the terminal arbors that were already in place on the tectum. This inference is consistent with the hypothesis of shifting terminals (Gaze, et al., 1974) and will be pursued more explicitly in the next paper (Easter and Stuermer, 1984). The need for shifting terminals is clear when one considers the rostral fascicles, which, as we have shown, originate from central retina. According to the earlier view of retinotectal organization (Attardi and Sperry, 1963; Horder, 1974; Meyer, 1979), an axon was believed to occupy a fascicle which coursed directly toward its termination site. We believe this to be the case for the most peripheral fascicle, but if it were true for the dorsorostral ones, then their axons should have originated from the ventrotemporal retinal quadrant (Jacobson and Gaze, 1964; Schwassmann and Kruger, 1965). In fact, the axons in each dorsorostral fascicle originated from both ventrotemporal and ventronasal quadrants. Moreover, axons from central retina terminate in central tectum, caudal to the fascicles through which, as we now know, they entered tectum (Fig. 2c). If a central retinal axon originally terminated rostrally and now terminates more caudally, then the terminal must have moved. If so, then the original site of termination, near the fascicle, must be linked to the current site of termination by an extrafascicular segment of the axon.

Figure 3 illustrates the sequence of events as we imagine them. It shows three stages in the life of three retinal ganglion cells and their axons. All are in the right ventral hemiretina and terminate in the left dorsal hemitectum. When they first grew into the tectum, their terminal arbors were all close to the fascicle through which they entered at the tectal margin (Fig. 3a). Later, after the retina and tectum had grown, the terminals shifted to new sites (Fig. $3 b$ ). The original terminal arbors have disappeared; their abandoned locations are given by the dotted lines. Note that the axons remained in the same fascicle through which they had originally arrived, but much of their fascicle has now been enveloped by new tectal tissue. Still later, the terminals have occupied new sites (Fig. 3c); the termination sites at the two earlier
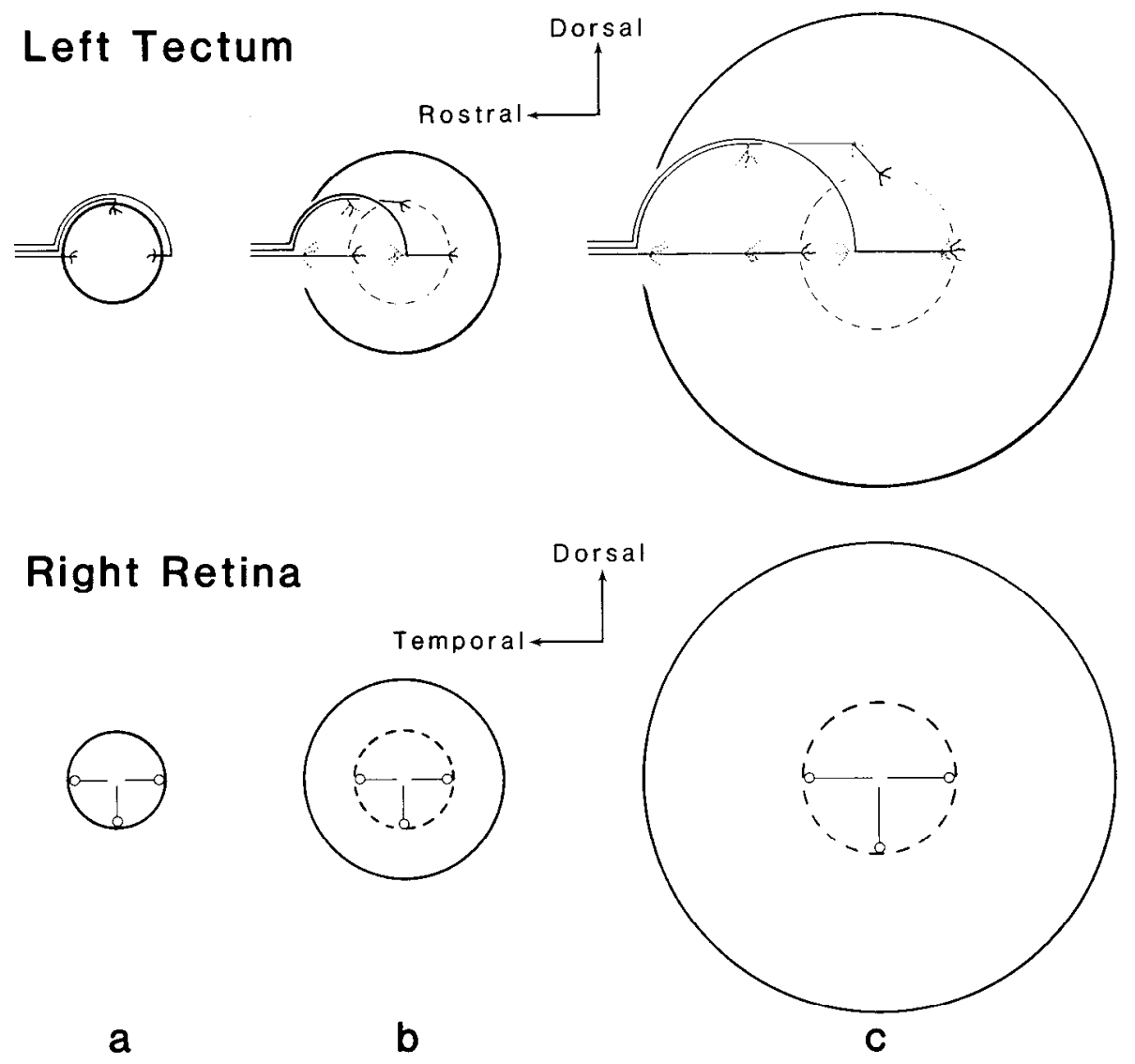

Figure 3. A proposed sequence of events. $a, b$, and $c$ represent three successively older stages in the growth of the retina and tectum. Below, the outer boundary of the retina is shown by the dark boundary. The dashed line gives the boundary of the earliest retina (the one in $a$ ). The three small circles are ganglion cell bodies, and the three lines are their axons, which converge on the optic disk at the center. Above, the contralateral tectum is seen in the perspective of Figure $2 a$. The terminals of the three ganglion cells project to retinotopic positions. The fascicle through which their axons enter is initially on the edge (a) but later becomes enclosed by the new tectal tissue. The dashed line shows the retinotopic termination of the ganglion cell bodies which lie on the dashed circle in the lower panels. The dimensions of the three retinas are scaled so that the numbers of cells in each are in the proportions, $1(a): 5(b): 10(c)$. The retina and tectum are assumed to grow by a combination of neurogenesis and stretch, as described by Johns and Easter (1977) and Raymond and Easter (1983). 
times are shown by dotted lines. Although this illustration shows each terminal in only three positions, we suppose that the shift has been a gradual one, in which the center of a terminal arbor moved slowly by the addition and elongation of sprouts on one side and the loss of old branches on the other.

Formation of tectal fascicles. The events which produce fascicles of axons in the tectum are unclear. Whenever tritiated thymidine is injected into a goldfish, cells in the germinal zones of both the retina and the tectum are labeled. This suggests that cell proliferation is a continuous process in both tissues. If so, then we might expect to see a continuous sheet of axons in the stratum opticum, rather than the fan of discrete fascicles (Fig. 1c). The segregation of axons into fascicles may occur after they have grown in. Alternatively, the formation of axons may be a discontinuous process, unlike the production of the parent cell bodies. The axons would then be expected to enter the tectum in waves, each wave following the preceding one after an interval during which the crescentic increment of tectum was added, devoid of retinal axons. We have no information which would enable us to favor one or the other of these alternatives.

The thickness of the partial anuli, 4 to $8 \%$ of the retinal radius, seems rather large if only one or two fascicles were labeled. If individual fascicles originate from discrete anuli, and adjacent fascicles from adjacent discrete anuli, then the minimum thickness $(4 \%)$ is consistent with the existence of about 25 separate fascicles. In fact, there are many more than that. In the tissue illustrated in Figure $1 c$ there are about 60 , although a firm number is not easy to establish because the fascicles sometimes coalesce and diverge (although they practically never cross one another). It seems probable that the ganglion cells that contribute axons to a given fascicle have neighbors (in the same partial anulus) that send their axons into another tectal fascicle, probably nearby. This is consistent with the observation that not all of the ganglion cells within the partial anulus are labeled through one or two adjacent fascicles. Of course, there is the alternative trivial explanation that all severed axons do not pick up the HRP. But if this were the only reason why all of the cells were not labeled, then we would not expect to see such thick partial anuli. Another alternative is that the HRP diffused to, and was picked up by, fascicles distant from the intended label site. This would explain the too-thick anuli, but this explanation is at odds with the selectivity of the label shown in the tectal whole mounts. A third alternative is that only a fraction of the retinal ganglion cells sent their axons into tectum, and those unlabeled cells within the boundary of the labeled partial anulus were cells which projected elsewhere. This explanation can be excluded with reference to the following paper (Easter and Stuermer, 1984). When HRP was applied to the tectal terminals of the retinal afferents, a much higher fraction of cells was labeled. Therefore, the majority, and perhaps all, of the retinal ganglion cells terminate in tectum. To recapitulate, the projection of retinal anulus to tectal fascicle must be slightly blurry. Near retinal neighbors can probably project into the same or nearby tectal fascicles. Conversely, retinal ganglion cells displaced from one another by up to about $4 \%$ of the retinal radius can probably project into the same fascicle. Earlier work with pulsed labels of tritiated thymidine (Johns, 1977; Meyer, 1978) showed that ganglion cells with similar birthdays were clustered more tightly than that. Therefore, we suggest two alternatives. Either ganglion cells of similar birth dates send out their axons at slightly different times, such that the late axons from one generation cluster at the sharply defined edge of the tectum with the earliest axons of a slightly later one; or the axons from a given generation of somata grow out synchronously but are sloppy in their selection of fascicles, some remaining on the very edge, others entering nearby fascicles already enveloped by tectum.

In the next paper (Easter and Stuermer, 1984) we leave the fascicles, in order to concentrate on the hypothetical extrafascicular segments of the axons.

\section{References}

Attardi, D. G., and R. W. Sperry (1963) Preferential selection of central pathways by regenerating optic fibers. Exp. Neurol. 7: 46-64.

Bodick, N., and C. Levinthal (1980) Growing optic nerve fibers follow neighbors during embryogenesis. Proc. Natl. Acad. Sci. U. S. A. 77: 4374-4378.

Cook, J. E., and T. J. Horder (1977) The multiple factors determining retinotopic order in the growth of optic fibers into the optic tectum. Philos. Trans. R. Soc. Lond. (Biol.) 278: 261-276.

Easter, S. S., Jr., and C. A. O. Stuermer (1984) An evaluation of the hypothesis of shifting terminals in goldfish optic tectum. J. Neurosci. 4: 1052-1063.

Easter, S. S., Jr., A. C. Rusoff, and P. E. Kish (1981) The growth and organization of the optic nerve and tract in juvenile and adult goldfish. J. Neurosci. 1: 793-811.

Fujisawa, H., K. Watanabe, N. Tani, and Y. Ibata (1981) Retinotopic analysis of fiber pathways in amphibians. I. The adult newt Cynops pyrrhogaster. Brain Res. 206: 9-20.

Gaze, R. M., M. J. Keating, and S. H. Chung (1974) The evolution of the retinotectal map during development in Xenopus. Proc. R. Soc. Lond. Biol. 185: 301-330.

Holt, C. E., and W. A. Harris (1983) Order in the initial retino tectal map in Xenopus: A new technique for labelling growing nerve fibers. Nature 301: 150-152.

Horder, T. J. (1974). Changes of fiber pathways in the goldfish optic tract following regeneration. Brain Res. 72: 41-52.

Jacobson, M., and R. M. Gaze (1964). Types of visual response from single units in the optic tectum and optic nerve of the goldfish. Q. J. Exp. Physiol. 49: 199-209.

Johns, P. R. (1977) Growth of the adult goldfish eye. III. Source of the new retinal cells. J. Comp. Neurol. 176: 343-358.

Johns, P. R., and S. S. Easter, Jr. (1977). Growth of the adult goldfish eye. II. Increase in retinal cell number. J. Comp. Neurol. 176: 331-342.

Mesulam, M. M. (1978). Tetramethyl benzidine for horseradish peroxidase neurohistochemistry: A noncarcinogenic blue reaction product with superior sensitivity for visualizing neural afferents and efferents. J. Histochem. Cytochem. 26: 106117.

Meyer, R. L. (1978) Evidence from thymidine labeling for continuing growth of retina and tectum in juvenile goldfish. Exp. Neurol. 59: 99-111.

Meyer, R. L. (1979) "Extra" optic fibers exclude normal fibers from tectal regions in goldfish. J. Comp. Neurol. 183: 883901

Meyer, R. L. (1980) Mapping the normal and regenerating 
retinotectal projection of goldfish with autoradiographic methods. J. Comp. Neurol. 189: 273-289.

Müller, H. (1952) Bau and Wachstum der Netzhaut des Guppy (Lebistes reticulatus). Zool. Jb. 63: 275-324.

Raymond, P. A., and S. S. Easter, Jr. (1983) Postembryonic growth of the optic tectum in goldfish. I. Location of germinal cells and number of neurons produced. J. Neurosci. 3: 10771091.

Rusoff, A. C. (1980) Paths of optic axons across the tectum of fish. Invest. Ophthalmol. Vis. Sci. Suppl. 18: 2.

Rusoff, A. C., and S. S. Easter, Jr. (1980) Order in the optic nerve of goldfish. Science 208: 311-312.

Scholes, J. H. (1979) Nerve fibre topography in the retinal projection to the tectum. Nature 278: 620-624.

Schwassmann, H. O., and M. H. Krag (1970) The relation of visual field defects to retinotectal topography in teleost fish. Vision Res. 10: 29-42.

Schwassmann, H. O., and L. Kruger (1965) Organization of the visual projection upon the optic tectum of some freshwater fish. J. Comp. Neurol. 124: 113-126.

Sperry, R. W. (1944) Optic nerve regeneration with return of vision in anurans. J. Neurophysiol. 7: 57-69.

Straznicky, C., R. M. Gaze, and T. J. Horder (1979) Selection of appropriate medial branch of the optic tract by fibres of ventral retinal origin during development and in regeneration: An autoradiographic study in Xenopus. J. Embryol. Exp. Morphol. 50: 253-267.

Stuermer, C. A. O., and S. S. Easter, Jr. (1982) Growth-related order of optic axons in goldfish tectum. Soc. Neurosci. Abstr. 8: 451 . 